\title{
“NÃO VEJO COMO ATUAR POLITICAMENTE SEM IDEIAS OU DISTANTE DA TRADIÇÃO UTÓPICA. ESCREVER SOBRE ESSAS TRADIÇÕES UTÓPICAS ME AJUDOU A MANTER ESSAS IDEIAS VIVAS PARA MIM. E HOJE ESSAS IDEIAS VALEM MAIS DO QUE NUNCA."
}

\author{
Entrevista com Russell Jacoby ${ }^{1}$
}

\section{Revista Malala (RM)}

Tendo em mente que se trata de uma discussão complexa e que toda definição pode ser genérica, podemos começar com a definição de intelectual. Como você definiria um intelectual?

\section{Russell Jacoby (RJ)}

Eu sempre parto de uma distinção acadêmica. 0 intelectual acadêmico é alguém que pensa e leva as ideias a sério. Um intelectual em sentido mais amplo é alguém que leva, que faz o debate na esfera pública. É o que chamo de intelectual público. Toda definição de intelectual que deixa de fora essa dimensão pública não me agrada. Embora associar os intelectuais ao trabalho com as ideias e ao aprendizado teórico seja uma definição precisa - quem trabalha com ideias é um intelectual -, a mim me interessa mais aquele que leva esse debate e esse aprendizado à esfera pública. Temos vários tipos de intelectuais: os da esfera privada, os da academia, mas é na esfera pública que há mais impacto. Por isso, minha preocupação tem sido o destino desses intelectuais públicos.

RM

Hoje a esfera pública não é diferente? Com a internet, blogs, redes sociais etc., isso tudo não tem uma dimensão semelhante ao que você chama de espaço de atuação dos intelectuais públicos?

$\mathrm{RJ}$

A questão do impacto deve ser discutida. Quem avalia esse impacto? Na internet, qualquer um pode ter um perfil público e uma presença pública (no sentido de não ser mais da esfera privada) e sem dúvida há benefícios óbvios nisso: não há qualquer mecanismo de filtro, não há edição (ou editores), mas, por outro lado, há também notórios aspectos negativos: há excessos, há perturbações. Na prática, ninguém mais se escuta. É isso que acontece quando todo mundo fala ao mesmo tempo.

\footnotetext{
1 Professor de História na University of California, em Los Angeles. Entrevista realizada por Ariel Finguerut, membro do Conselho Editorial da Revista Malala. A entrevista ocorreu por Skype no dia 25/9/2018. Transcrição e tradução para o português de Ariel Finguerut.
} 


\section{$\mathbf{R M}$}

É como ter mais gente escrevendo que lendo.

RJ

Sim, certo. É como aquele cartum que saiu uma vez no NYT. Numa suposta feira de livro, na mesa está o leitor e, na plateia, os escritores querendo a atenção do leitor (risos). Temos um leitor para muitos autores. Todo mundo está escrevendo na internet, mas ninguém lê. A internet é um meio que altera nossa atenção, e nossa capacidade de atenção está em declínio. Vejo isso também entre meus alunos. A capacidade deles para ler e escrever está em declínio. As pessoas leem postagens curtas em blogs e nas redes sociais, mas não leem livros. Isso é um problema.

\section{$\mathbf{R M}$}

De certa forma, esse problema com estudantes universitários não é novo. Richard M. Weaver, no clássico Ideas have consequences, originalmente publicado em 1948, já alertava sobre isso, sobre o desinteresse pelos clássicos da literatura ocidental, etc.

RJ

Sim, é um fato. As pessoas não estão lendo. Vejo isso empiricamente com meus estudantes. Eles não leem ou leem cada vez menos. É como se fosse uma epidemia de distúrbio de déficit de atenção. E isso se tornou algo que afeta o público em geral.

\section{RM}

Em paralelo a essa dificuldade, percebo também uma tendência à reprodução na academia. Muitas vezes, parece que apenas há ascensão na carreira acadêmica se você reproduzir, seguir determinadas tendências e se filiar às "escolas", seguindo e concordando com a pesquisa de seu orientador, de seus professores (...).

\section{RJ}

Sim, eu entendo seu raciocínio. A universidade não está imune a pressões. Aquele velho ditado: "Publicar ou perecer" não deixa de ser uma reafirmação de uma lógica básica do capitalismo, ou seja, é preciso "produzir para se manter vivo". Quem não produz está fora dos negócios. E, nessa lógica, ou você tem um produto, algo que o coloca como um ator no mercado, ou você está fora, como um falido. Então, esse ambiente cria uma pressão e muitos estudos já foram feitos mostrando que a pressão para publicar produz artigos e resultados de pesquisas que são apressados, sem revisão, com fontes comprometidas, etc. Sem falar que são produções com "fim em si mesmo", sem ou com baixo impacto. E isso pode chocar, mas me parece algo óbvio. A universidade, por mais que tente ser diferente, é um reflexo dessa realidade que está na sociedade como um todo, ou seja, a universidade espelha a hierarquia, a busca pelo status, etc.

Eu não acompanhei as últimas pesquisas do campo da sociologia que estuda a 
universidade, mas, se olharmos esse universo de "citações" dos rankings de impacto, etc., há um círculo vicioso: quem é mais citado é quem mais cita. É uma lógica totalmente circular movida por poder e prestígio. É algo que não tem nenhuma relação com a qualidade dos trabalhos. É bem simples: se alguém é "importante", ele é muito "citado". Se você não é importante, logo você não é citado. No livro em que estou trabalhando no momento eu falo um pouco sobre Walter Benjamin e havia um escritor e roteirista que escreveu um livro não acadêmico sobre Benjamin e ele, por não ser da academia, é simplesmente ignorado pelos professores e acadêmicos "especialistas em Walter Benjamin". Na perspectiva dos acadêmicos, não haveria por que citar um autor ou discutir um livro que não daria "nada em troca". A academia, nesses termos, é uma rede fechada. Se você não faz parte, você está fora do debate deles, você se torna um outsider.

\section{RM}

Mas e o fator impacto? Intelectuais também não precisam de impacto para conquistar fama e assim também ter mais chances de ascensão? Nesse sentido, o poder não é uma força de sedução aos intelectuais? Estar perto do poder, assessorar, etc. não amplia o impacto dos intelectuais?

\section{RJ}

Você quer dizer na política, não? Esse tem sido o dilema dos intelectuais desde Platão. O dilema da sedução do poder! O que seduz é a ideia de ver as ideias na prática, sair da teoria e ir para a ação. E isso de fato é uma grande tentação e tem seduzido os intelectuais de Platão a Heidegger: a ideia de aderir ao poder - e recentemente os neoconservadores aqui nos EUA têm sido bem-sucedidos nesse processo. Não há nada de novo nisso. No meu livro Os últimos intelectuais, ${ }^{2}$ eu escrevi que a esquerda dominou os departamentos de literatura das universidades enquanto a direita dominou o Departamento de Estado no governo dos EUA (risos). Então, nós temos professores marxistas dando cursos de literatura sem qualquer chance de impacto, e os conservadores, de certa forma, foram "espertos" e se prepararam para ser advogados, políticos, etc. e chegaram aos círculos mais restritos de decisão. Enquanto isso, os professores marxistas ficam na universidade e, quando escrevem, não conseguem escrever uma linha que seja bem compreendida pelo grande público.

\section{RM}

Equando intelectuais mudam de lado? Por exemplo, de marxistas para conservadores. Por que mudar de lado?

\section{RJ}

(Risos) Bom, é difícil rastrear apenas um motivo para mudar de lado. Pode haver $\overline{{ }^{2} \text { Ed. USP. 1990. SP. }}$ 
várias motivações. Oportunismo é parte da equação. Pensando alto, um marxista pode pensar: "Qual o futuro do marxismo?" e, além disso, há algo como "choque de realidade". Qual experiência marxista é edificante? Facilmente, quando se pensa em regimes vigentes, o da Venezuela ou o da Coreia do Norte não são o que poderíamos chamar de "modelos de inspiração". Um dos primeiros livros que eu escrevi discutia essa "dialética da derrota" ${ }^{3}$ e ali mostro que os marxistas sempre foram seduzidos pela ideia de "sucesso", e esses modelos econômicos marxistas, como o stalinismo ou o maoismo, traduzem essa busca. E, quando os professores marxistas fazem uma reflexão sobre os êxitos desses modelos, os resultados novamente não são inspiradores. Claro que há uma sedução, quando se é jovem, pela ideia de esquerda. Isso sempre foi assim, mas, a partir da queda da URSS, com toda a situação que se tornou pública nas ex-repúblicas socialistas, nada disso ajuda aqueles que eventualmente fizerem uma autocrítica querendo seguir no marxismo. E hoje, no debate, é difícil sustentar certos argumentos por falta de referências. Quem vai apontar para a Venezuela como exemplo? Mesmo Cuba (...) não representa bons exemplos. Acaba sendo uma defesa na contramão da história. Claro que ainda é possível pensar em modelos alternativos. Eu mesmo faço isso.

\section{RM}

O dilema do fracasso dos modelos marxistas nos leva a outro tema caro aos intelectuais: a violência. Muitas vezes, junto com os modelos econômicos ou com as revoluções, vem o dilema da violência. Como justificá-la, quando aplicá-la, etc.? E, muitas vezes, cabe aos intelectuais a tentativa de explicar os processos revolucionários e eles acabam tendo que, de um modo ou de outro, lidar com o fator violência. Como você vê essa relação entre intelectuais e a violência?

\section{RJ}

(risos) Essa é uma grande pergunta. Não sei se tenho condições de responder. Merleau Ponty, em seu livro Humanism and terror: an essay on the communist problem, retoma um argumento que remete à Revolução Francesa: a ideia é que, para avaliar ou discutir a violência que parte da esquerda, é preciso também avaliar o outro lado, ou seja, a violência da direita. 0 argumento seria o seguinte: a violência da Revolução Francesa seria paralela à violência diária que o capitalismo proporciona às pessoas. Esse argumento é antigo, mas ele até hoje tem algo de justo e nos faz pensar que a violência pode ter diferentes e várias formas distintas. E precisamos ter o cuidado de não atribuir o status de violência apenas aos processos revolucionários. É preciso olhar também para a violência que está na vida cotidiana. Por outro lado, novamente a pesquisa histórica não ajuda na defesa das revoluções. Basta pensar novamente no stalinismo ou no maoismo. Há uma dialética antiga que discute como produzir uma "boa sociedade", mas (...) e se as

${ }^{3}$ Cf. Dialectic of Defeat. Contours of Western Marxism. https://www.cambridge.org/core/books/dialecticof-defeat/A86855856E59BB5BC95FABF659FE933C. Acessado em 29/09/2018. 
pessoas não são exatamente "boas"? E esse dilema me parece que nunca foi resolvido. Pessoas cercadas de seus problemas querem uma sociedade melhor e, se elas têm vidas tão problemáticas, como criar uma sociedade melhor? É uma questão difícil. E não temos bons resultados nessa busca. Revolucionários podem ser pessoas cheias de vícios como qualquer outra pessoa.

\section{RM}

Isso me lembra outro dilema clássico das revoluções: aquele que faz a revolução hoje acorda no dia seguinte já um conservador, pois precisa manter-se no poder.

\section{RJ}

(risos). Sim, certo. Isso é algo comum na história. Muitas vezes, criar uma revolução é parte de uma justificativa política. E, às vezes, tornar-se conservador não é uma escolha, mas uma consequência de uma transformação. É o dilema entre o projeto político e o projeto pessoal. Alguns transformam o projeto político em seu projeto pessoal, e ser conservador pode não ser escolha. Você não faz uma revolução com burocratas! Mesmo que sejam burocratas que aderem ou almejam essa revolução. Há o risco de eles se tornarem ou serem burocratas reacionários. Isso é parte do dilema dos burocratas. Muda o regime, mas eles permanecem burocratas (risos). Podemos discutir se há algum tipo de "personalidade revolucionária", mas eu considero esses dilemas não resolvidos. É possível ser "vegano" e "terrorista"? É parte do aspecto mais bizarro do nazismo notar que muitos que aderiram ao regime eram também defensores dos direitos dos animais. Isso é um debate peculiar, mas o ponto é pensarmos como é essa relação entre a vida privada e a vida política/pública. Alguém pode ser pacífico e até pregar o pacifismo na esfera privada e, ao mesmo tempo, ser extremante violento e capaz de defender e participar de atrocidades na esfera política.

\section{RM}

Tornou-se popular em nosso tempo um ambiente de embate e de dúvida em relação aos intelectuais. Isso aparece na chamada "era da pós-verdade", pautada pela disseminação de teóricas conspiratórias e pelo negacionismo - seja em torno de temas contemporâneos, como "mudanças climáticas", seja de fatos históricos, como genocídios e perseguições étnico-religiosas. Curioso é que todos esses processos exigem uma legitimação e uma ativa participação intelectual. Você diria que os intelectuais são parte do problema ou eles têm alguma saída para essa crise?

\section{RJ}

De muitas maneiras, eles são parte do problema certamente. Mas veja novamente os intelectuais conservadores. Não é que eles sejam melhores, mas talvez sejam mais espertos; eles se adaptam melhor. Enquanto a esquerda está estudando literatura, a direita 
está tentando entender o poder e o Estado. Mas, em termos de anti-intelectualismo, os intelectuais são parte da solução. Não há saída para esse problema que não seja pensar e levar o pensamento e as ideias a sério. E, nesse sentido, sim, nós precisamos de intelectuais. Há uma vertente histórica clássica no anarquismo que é anti-intelectual, projetando a figura do intelectual como parte da elite. Não que isso seja errado, mas é uma vertente de pensamento perigosa. 0 próprio Marx era, sem dúvida, um intelectual. Portanto, se um pensamento radical de esquerda abraçar o anti-intelectualismo, afetará negativamente a todos. A ideia dos intelectuais como parte da elite leva a pensá-los como uma espécie de parasita, um grupo que não produz, que não tem valor e que, portanto, não é aceitável. Sem os intelectuais nós não avançamos.

\section{$\mathbf{R M}$}

Para além, então, dos intelectuais cuja importância acaba de argumentar, e se pensarmos nas utopias? Há utopia em nosso tempo? Qual a importância do pensamento utópico?

RJ

Já escrevi sobre esse tema e creio que continuo um idealista, pois não consigo me imaginar como um ser político sem o mundo das ideias e sem discutir ideias que permitam pensar em como a sociedade poderia ser diferente. Vivemos uma era muito cínica e reacionária (risos) e quem é idealista é visto como alguém que, para a sociedade, não projeta esperança. Ou pior: são vistos como terroristas. Eu não vejo dessa forma. A tradição de pensamento utópica na forma mais autêntica não era particularmente violenta. Eram ideias sobre o trabalho, sobre o ser humano e sobre a sociedade, e a muitas dessas ideias - independentemente de terem sido aplicadas ou não - devemos nos apegar e prestar atenção. Não vejo como atuar politicamente sem ideias ou distante da tradição utópica. Escrever sobre essas tradições utópicas me ajudou a manter estas ideias vivas para mim. E hoje essas ideias valem mais do que nunca.

\section{RM}

Obrigado pela entrevista.

DM

Obrigado. 